\title{
Comportamento biológico de matriz scaffold acrescida de células progenitoras na reparação óssea
}

\author{
Bone marrow progenitor cells enriched scaffold biological behavior in bone repair \\ Débora Cristina Olsson $^{{ }^{*}}$ Ney Luis Pippi ${ }^{\mathrm{II}}$ Guilherme Kanciukaits Tognoli ${ }^{\mathrm{I}}$ \\ Alceu Gaspar Raiser ${ }^{\text {II }}$
}

\section{-REVISÃO BIBLIOGRÁFICA-}

RESUMO

A engenharia tecidual desenvolve e manipula células ou tecidos para a reconstrução de novos órgãos $e$ tecidos. A perda ou a falência da função de partes teciduais alteradas ou lesadas torna-se um problema severo à saúde animal e uma indicação para tratamento é o transplante para substituir a função biológica perdida. Vários animais são afetados por estes problemas, razões estas que indicam a necessidade de desenvolvimento de terapias alternativas para tratar perdas ósseas. Estudos experimentais contribuem para avanços da medicina regenerativa, como a engenharia de tecidos, com o objetivo de desenvolver suportes sintéticos ou utilizar arcabouços naturais, conhecidos como scaffold, que substituam as funções fisiológicas do tecido ósseo. Atualmente para, a obtenção destes objetivos utilizam-se também, de forma genérica, combinações específicas com células progenitoras (CP) da medula óssea (MO) do próprio paciente ou doador que são distribuídas em um material de suporte tridimensional com propriedades adequadas, gerando um material híbrido cujas características podem ainda ser moduladas para então ser reinserido no paciente. O objetivo desta revisão é apresentar informações sobre o comportamento biológico de materiais sintéticos e naturais apropriados para implantes ósseos, acrescidos ou não de CP, para o estímulo do processo reparativo de tecido ósseo.

Palavras-chave: Scaffold, comportamento biológico, reparação óssea, células progenitoras.

\section{ABSTRACT}

Tissue engineering involves the manipulation and the development of cells aiming to create and/or regenerate organs and tissues. Function failure of injuried tissues is a severe animal health problem, nevertheless, the transplantation has been indicated to treat and replace the biological function. A large amount of animals are affected by those problems, and for this reason it is necessary to find alternative therapies to treat bone losses. Studies such those involving tissue engineering have contributed to regenerative medicine advances, to developed synthetic and natural scaffolds. To pursue these objectives, specific combinations of autologous or alogenous bone marrow progenitor cells seeded over a three-dimension scaffold with adequate properties, creating a hybrid material that can be modulated to patient reinsertion. In this review, information about synthetic and natural biological materials indicated to bone grats, combined or not with progenitor cells, aiming to stimulate bone healing process are presented.

Key words: Scaffold, biological behaviour, bone repair, progenitor cells.

\section{INTRODUÇÃO}

A capacidade regenerativa do tecido ósseo é um mecanismo fascinante, no entanto, em casos de perda ou dano extenso, essa propriedade pode ficar limitada, alterando a fisiologia tecidual (LUTOLF et al., 2003). Como opções terapêuticas, são utilizados enxertos autógenos, alógenos, aloplásticos, xenogênicos e fatores de crescimento, porém, ainda é necessário encontrar técnicas e materiais auxiliares ao reparo de grandes

\footnotetext{
IPrograma de Pós-graduação em Medicina Veterinária, Departamento de Clínica de Pequenos Animais, Laboratório de Cirurgia Experimental, Universidade Federal de Santa Maria (UFSM). Rua Adriano Chaves, 199, apt ${ }^{\circ} 101$, 97105-010, Camobi, Santa Maria, RS, Brasil. E-mail oldeby@yahoo.com.br. *Autor para correspondência.

"Departamento de Clínica de Pequenos Animais, UFSM, Santa Maria, RS, Brasil.
} 
defeitos ósseos decorrentes de fraturas cominutivas ou multifragmentares, as quais apresentam maiores dificuldades de tratamento (OLIVEIRA et al., 2003). Dentre as técnicas de eleição, a enxertia óssea de ossos homólogos na ortopedia veterinária é um meio prático e seguro (GIOSO et al., 2002).

A principal vantagem no enxerto autógeno é a transferência de células osteoprogenitoras e matriz óssea, que são mais ativas durante o período intenso de crescimento ósseo (PAGLIOSA \& ALVES, 2007). Nos métodos tradicionais de tratamento que utilizam enxertos autólogos ou autógenos, a resposta osteogênica é superior, entretanto, não são destituídas de problemas pós-cirúrgicos, como as infecções e ou rejeições imunológicas (DEUEL, 1997; BARBANTI et al., 2005). Terapias disponíveis para esses tipos de afecções incluem também a reconstrução cirúrgica (GIOSO et al., 2002), tratamentos com fármacos, dispositivos biomédicos e utilização de próteses sintéticas (DEUEL, 1997). Porém, essas práticas apresentam limitações pela escassez de materiais e custo elevado, assim como a capacidade de as células em neoformação manterem sua função dentro do scaffold em que são estocadas, também pode interferir na osteogênese (LANGER \& VACANTI, 1993).

Terapias alternativas, consideradas promissoras, com CP da MO, para ativar a osteogênese e ampliar as possibilidades terapêuticas são investigadas, no entanto, estão relacionadas com a modificação do microambiente tecidual que determina o caminho que a regeneração deve seguir (NARDI \& MEIRELLES, 2006; PAGLIOSA \& ALVES, 2007). O desenvolvimento da engenharia de tecido ósseo baseada na cultura in vitro dessas $\mathrm{CP}$, previamente semeadas num suporte biológico ou sintético, tridimensional, conhecido com scaffold (suporte, matriz tridimensional, arcabouço, estrutura, apoio), forma um meio ou microambiente apropriado para as células se organizarem em estruturas funcionalmente similares ao tecido original (BURG et al., 2000; GOMES et al., 2003). Este meio apropriado, denominado matriz extracelular (MEC) (TENÓRIO, 2003), de natureza biodegradável, permite a adesão celular ao suporte, a proliferação e segregação da MEC específica do tecido ósseo, até a obtenção de um substituto artificial funcional com características do tecido original (MARTINEZ \& ARAÚJO, 2004). As MECs utilizadas facilitam a localização e a liberação de células para sítios específicos do organismo, definem e mantém um espaço para a formação de novos tecidos como estrutura apropriada, e guiam o desenvolvimento de novos tecidos (GOLDBERG et al., 2003).
Como meio apropriado, os scaffolds devem possuir unidades moleculares que possibilitem modificações e taxa controlada de biodegradação, não desenvolver toxicidade tópica ou sistêmica, ter propriedades para promover ou inibir interação célulamatriz e célula-célula, apresentar respostas imunes à inflamação, ser material de fácil produção ou aquisição e purificação e possuir compatibilidade com a substância química, com soluções aquosas em condições fisiológicas (HOLMES, 2002). O objetivo desta revisão é apresentar informações sobre o comportamento biológico de materiais sintéticos e naturais, apropriados para implantes ósseos, conhecidos como scaffold, acrescidos ou não de CP, que se organizam em estruturas similares ao tecido original para o sucesso de reparação de tecido ósseo.

\section{Influência da Matriz Extracelular (MEC)}

A MEC é a organização supramolecular de diversas proteínas estruturais e polissacarídeos nos tecidos conjuntivos, compreendendo colágeno, glicoproteínas não-colagenosas, proteoglicanos, glicosaminoglicanos, elastina e ácido hialurônico, que preenchem os espaços extracelulares (THOMAS \& ANGLARET, 1999). Estes componentes geram, portanto, a MEC do estroma medular (BURG et al., 2000). Alguns componentes fundamentais sobre a MEC devem ser cuidadosamente estudados, principalmente quando o scaffold for usado como suporte para células em sistema de cultura (GOMES, 2004).

Essas matrizes não devem apenas preencher espaço, mas sim devem estar associados a uma resposta biológica específica disparada por sinais que incluem: correntes elétricas, conformação molecular, estado de agregação ou propriedades físico-químicas que quando em contato com células cultivadas ou in natura, com ou sem plasma rico em plaquetas, permitam a permeação de nutrientes e a incorporação ao tecido receptor (WILLIAMS \& DOHERTY, 1994; PAGLIOSA\& ALVES, 2007). Além disso, essas matrizes devem sustentar crescimento celular por apresentar propriedades mecânicas condizentes em relação ao tecido a ser reconstruído, induzir respostas celulares mais rápidas ou ainda possuir intrinsecamente propriedades diretamente relacionadas com a remodelagem do tecido, como ocorre nos tecido nervoso e ósseo em relação a propriedades elétricas do novo material (PARTRIDGE et al., 2002).

Para isso, os desafios atuais são direcionados ao entendimento das relações entre composição química, cristalinidade, morfologia do suporte e degradação desses scaffolds. Apesar de alguns materiais sintéticos apresentarem sucesso em procedimentos cirúrgicos, quando um órgão ou 
um tecido não pode ser reparado, a alternativa viável é repô-lo com um implante obtido de um material biocompatível (CAMILO et al., 2006). A utilização de células da MO, está sendo uma alternativa para o sucesso de tratamentos com implante de materiais sintéticos ou naturais, uma vez que estas células podem ser facilmente colhidas do próprio paciente, por métodos não-invasivos e em quantidades numéricas suficientes para a sua incorporação (HOLMES, 2002). Além disso, a MO, por ser fonte de células autólogas, minimiza a transmissão de doenças e/ou a rejeição (PAGLIOSA \& ALVES, 2007).

Estudos em casos de defeitos por nãounião, tratados com uma matriz alogênica com uma única aplicação de aspirado da $\mathrm{MO}$, resultou em regeneração óssea assegurada em $50 \%$ dos casos que receberam matriz alogênica, permitindo a retenção das células adicionadas e servindo como agente osteopromotor (KRAUS \& KIRKED-HEAD, 2006). Portanto, as interações do ambiente com a MEC consistem no desenvolvimento de uma terapia óssea, substituta às existentes e com potencial para ser utilizada na prática clínica (LANGER \& VACANTI, 1993).

\section{Enxertos ósseos e CP}

O processo natural de regeneração óssea é suficiente para efetuar restauração oportuna da integridade do tecido para a maioria das fraturas quando há um ambiente hormonal, metabólico e mecânico apropriado ou quando esse ambiente é desenvolvido por enxertos fixadores ou pelo processo de incorporação de scaffolds, como, por exemplo, o osso esponjoso (CANCEDDA et al., 2003). A revascularização proporciona a integração do enxerto, assim, o osso esponjoso apresenta penetração vascular mais fácil que o compacto (HABAL, 1992). Os implantes cortico-trabeculares apresentam melhores resultados por possuírem resistência mecânica e a incorporação tecidual acontece por osteocondução ou osteoindução (GLOWACKI, 1992). Os materiais para enxerto ósseo osteogênicos estimulam a formação do osso diretamente a partir dos osteoblastos, incentivando a transferência de células (BRUDER \& FOX, 1999). Os osteoindutores induzem a diferenciação de células mesenquimais em osteo ou condroblastos, estimulando a formação óssea no local ou em sítio heterotópico (CANCEDDA et al., 2003), enquanto os osteocondutores são geralmente inorgânicos e permitem aposição de um novo tecido ósseo na sua superfície, requerendo para isso a presença de tecido ósseo pré-existente como fonte de células osteoprogenitoras (MASTERS, 1988), estimulando o meio mecânico biológico à regeneração (MUSCHLER \& MIDURA, 2002).

Diversos materiais têm sido empregados em defeitos intra-ósseos, como o enxerto mineralizado ou desmineralizado liofilizado, as cerâmicas biocompatíveis, os vidros bioativos e os polímeros (HERCULIANI et al., 2000; GOMES et al., 2007). Os derivados sintéticos, como a hidroxiapatita e o fosfato de tricálcio, têm recebido atenção como material de preenchimento, espaçadores e substitutos para enxertos ósseos devido a sua biocompatibilidade, bioatividade e características de osteocondução em relação ao tecido hospedeiro (MUSCHLER \& MIDURA, 2002). Segundo MASTERS (1988), a degradação da hidroxiapatita pode ocorrer por reabsorção mediada por osteoclastos ou dissolução química. De acordo com OONISHI et al. (1997), o mecanismo de reabsorção da hidroxiapatita pode envolver a degradação das partículas à medida que ocorre a formação do novo osso no interior dos poros intragranulares da matriz.

Precursores celulares, MECs e interações com células endoteliais determinam a manutenção ou liberação das células hematopoéticas do microambiente da MO para o sangue periférico. Conseqüentemente, mudanças na afinidade ou na quantidade de moléculas de adesão expressas no estroma da MO ou nos precursores das células do sangue durante o desenvolvimento normal afetarão a adesão celular (NARDI \& MEIRELLES, 2006). As CP utilizadas, por possuirem potencial osteogênico, são isoladas por várias técnicas (COOPER et al., 2001). O cultivo in vitro de CP da MO na presença de dexametasona, ácido ascórbico, e glicerofosfato resultam em células de linhagem de osteoblástica (HAYNESWORTH et al., 1992), que assumem um aspecto cuboidal por uma indução passageira de atividade da fosfatase alcalina. Essas células expressam proteína mRNAs em contato com a deposição de MEC, formada de hidroxiapatita, resultando na confirmação de que as CP isoladas da MO e cultivadas se tornam células ósseas (JAISWAL et al., 1997).

Estudos in vivo documentam o potencial osteoblástico das CP isoladas da MO e expandidas em cultura, inoculadas a scaffolds cerâmicos porosos e implantandos em tecido subcutâneo e ósseos de animais. Esses estudos verificaram que ocorreu vascularização entre os poros em implantes celulares e nos acelulares não observaram neoangiogênese e a modificação destas técnicas também demonstrou que CP podem ser induzidas a formar linhagens condroblásticas (BARRY, 2003). Neste aspecto, as CP do estroma da MO são consideradas a fonte mais produtiva de células osteogênicas (CAPLAN \& BRUDER, 2001). 
DEL CARLO et al. (2003), estudaram o polímero de mamona acrescido de cálcio e verificaram a ocorrência de osteogênese e osteocondução, com formação óssea progressiva, principalmente quando adicionado de CP. Adicionalmente, os autores observaram a migração de capilares, de tecidos perivasculares e de células osteoprogenitoras num processo inicial de tecido fibrovascular invadindo a estrutura porosa superficial, seguido da deposição direta de osso e concluíram que esse arcabouço passivo se comportou como um espaçador osteocondutor.

MECs contendo colágeno, utilizados como scaffold, possuem propriedades privilegiadas como biomaterial em diversas aplicações para a reconstrução de tecidos moles (MATSUI, 1996), revestimento de queimaduras, para reconstrução de derme (SAKIEL, 1995) e o suporte para crescimento de nervos periféricos (BLACKSHAW et al., 1997), como agente hemostático, suporte para crescimento de fibras musculares lisas, células endoteliais, hepatócitos e condrócitos (RAO, 1995). Além de serem utilizadas como membranas esponjosas, gel, pós, filmes e tubos, entre outros, promovendo grande interação celular, revestem próteses sintéticas vasculares por apresentarem maior hemocompatibilidade (GUPTA \& KASYANOV, 1997). Estudos com cultura de células da MO em scaffolds biodegradáveis à base de amido de milho num bioreator de perfusão constituiu um modelo para o estudo de mecanismos biológicos associados ao processo de formação de tecido ósseo, o que, por sua vez, contribuiu para a avaliação e a melhoria de estratégias de engenharia de tecidos ósseos (GOMES, 2004).

Os enxertos ósseos corticais têm sido utilizados em mamíferos para correção de defeitos, agindo como estruturas de sustentação de peso e como suporte para crescimento de osso novo no hospedeiro. O grupo de pesquisas do Laboratório de Cirurgia Experimental (LACE), da Universidade Federal de Santa Maria (UFSM) formado por docentes, graduandos e pós-graduandos em medicina veterinária, desenvolve estudos com scaffolds em tecidos há alguns anos (RAISER et al., 2001; BRUN et al., 2002; CONTESINI et al., 2004; GOMES et al., 2007), porém, desde 2005 o grupo de pesquisas tem realizado projetos científicos relacionadas às $\mathrm{CP}$ de cães, colhidos da $\mathrm{MO}$, associadas à scaffold, em lesões em tecidos ósseos (SALBEGO et al., 2007; OLIVEIRA et al., 2007), tendíneo, nervoso e corneano. Os scaffolds de escolha são os de origem biológica e também os de tecidos macerados do próprio órgão que se deseja o favorecimento celular. Recentemente, uma osteossíntese com fixador esquelético externo do tipo
II associado a enxerto ósseo alogênico conservado em mel como MEC foi utilizado para o transplante de CP da MO em um cão com não-união em uma fratura de tíbia, ocasionada por trauma automobilístico, obtendose um crescimento ósseo regenerativo com 15 dias, comprovado por avaliação radiográfica e resultado clínico favorável com deambulação. O resultado obtido demonstrou ser um método simples, rápido e aplicável, o que reforça a idéia da eficácia da consolidação com associação de enxerto ósseo conservado acrescido de células CP da MO (SERAKINCI \& NICOL, 2006; OLSSON et al., 2007).

Mesmo com os sucessos alcançados, ainda há muito para pesquisar. Um componente crítico da criação e renovação tecidual é a implantação de um número de células adequadas para ser obtida uma regeneração competente. Embora esses desafios permaneçam, células-tronco ou CP in natura ou cultivadas possibilitarão a expansão de linhagens celulares para o sucesso da engenharia tecidual, minimizando as complicações da regeneração do tecido ósseo (SOARES, 2005).

\section{Estrutura e classificação dos Biomateriais}

A estrutura do scaffold segundo TAMAI et al. (2002) deve possuir cinco fatores considerados desejáveis: superfície que permita adesão e crescimento celular; nenhum componente ou subproduto de sua degradação deve provocar reações inflamatórias ou tóxicas; apresentar estrutura tridimensional; a porosidade deve proporcionar elevada área superficial para interação célula-scaffold; ter espaço para a regeneração da MEC (Tabela 1) (EDWARDS et al., 2004). A porosidade dos scaffolds influencia o desenvolvimento das células osteoblásticas e, em combinação com as condições de cultura para a funcionalidade dos tecidos formados in vitro (GOMES, 2004), facilitando a chegada de células indiferenciadas desde o periósteo, endósteo e MO, que se localizam entre as trabéculas do implante e se diferenciam em osteoblastos, formando novo osso (DASSO et al., 1998).

Os materiais são classificados em naturais, cerâmicos, metálicos, poliméricos e compósitos. No entanto, para a aplicação em implantes, os materiais podem ser divididos de outra forma, dependendo da interação com o meio (Figura 1). Nesta, os biomateriais são classificados pela origem e pelas aplicações a que se destinam, sendo esta última dividida em três grupos: substituição de tecidos moles, como exemplo, implante de matriz óssea desmineralizada xenogênica em músculos (EDWARDS et al., 2004), substituição de tecidos duros, como a resina acrílica autopolimerizável 
Tabela 1 - Parâmetros estruturais do scaffold para aplicação na engenharia tecidual.

\begin{tabular}{ll}
\hline Função do scaffold & Característica necessária para cada função do scaffold \\
\hline Não provocar resposta inflamatória de toxicidade in vivo & Deve ser biocompatível, não-tóxico e não-carcinogênico \\
Ajudar o crescimento tridimensional de tecidos e órgãos & Forma específica tridimensional \\
Semear uniformemente alta quantidade de células & Apresentar alta porosidade e alta conectividade entre os poros \\
Permitir adesão, proliferação e diferenciação celular & Possuir superfície química e topografias apropriadas \\
Permitir interações significativas entre a superfície celular e anexos & Relação área de superfície X volume \\
$\begin{array}{l}\text { Promover proliferação e migração celular e conduzir a crescimento } \\
\text { de tecido ao longo do scaffold }\end{array}$ & $\begin{array}{l}\text { Tamanho de poros apropriados para permitir a penetração de } \\
\text { células e a inteconectividade entre elas }\end{array}$ \\
$\begin{array}{l}\text { Dirigir e orientar de células da Matriz Extracelular para formação de } \\
\text { novo tecido }\end{array}$ & Orientação correta das fibras dentro do scaffold \\
Permitir o movimento de nutrientes dentro e fora do scaffold & Alta porosidade e interconectividade entre os poros \\
Degradação do scaffold para permanecer somente tecido natural & $\begin{array}{l}\text { Taxa de degradação de scaffolds não devem ser tóxicos nem } \\
\text { promover inflamação in vivo }\end{array}$ \\
$\begin{array}{l}\text { Integridade estrutural suficiente para reter forma in vivo com tensão } \\
\text { mecânica suficiente para apoiar o tecido em desenvolvimento e } \\
\text { resistir em forças in vivo }\end{array}$ & $\begin{array}{l}\text { Scaffold deve igualar-se às propriedades mecânicas do tecido } \\
\text { em desenvolvimento }\end{array}$ \\
\hline
\end{tabular}

(Fonte: Adaptado de EDWARDS et al., 2004).

(RAISER et al., 2001) e materiais para o tecido cardiovascular, como o implante de traquéia na microanastomose arterial (CONTESINI et al., 2004). Nas terapias aplicadas a cardiopatias, as CP do paciente são cultivadas in vitro e reinseridas na lesão, sem intermédio do arcabouço. Os scaffolds atualmente produzidos ainda estão aquém do desejado, pela dificuldade em compatibilizar propriedades biológicas com requisitos mecânicos (SOARES, 2005). Avanços significativos têm sido feitos em regeneração de tecidos pelo uso de CP (CAPLAN \& BRUDER, 2001), em que se percebe que as células aderidas são viáveis no tempo entre 24 a 72 horas (EDWARDS et al., 2004). O estudo da diferenciação celular induzida pela composição do suporte, arcabouço ou scaffold, pela morfologia e pela presença de fatores de crescimento é vantajosa (WILLIAMS \& DOHERTY, 1994), pois permite que as CP permaneçam no local da lesão quando implantadas in vivo, impedindo que migrem para outro local indesejado do organismo (BENSAÏDE et al., 2003).

Os materiais orgânicos autógenos apresentam resultados mais previsíveis durante uma substituição ou reconstrução de lesões, no entanto, este biomaterial tem a inconveniência do procedimento cirúrgico da fonte doadora, além de disponibilidade limitada. Um exemplo destes é o osso esponjoso, que, além de fornecer fatores de indução óssea, possui estrutura porosa que favorece o crescimento vascular e osteogênico em seu interior (HENCH, 1998). Uma opção aos auto-enxertos são os materiais orgânicos alógenos (OLIVEIRA et al., 2003), os quais são provenientes de outro indivíduo da mesma espécie, porém, podem oferecer riscos de contaminação e/ou rejeição. Exemplos desses materiais é o osso esponjoso na forma descalcificada ou não e proveniente de bancos de ossos (GOMES et al., 2007). Os materiais xenógenos, porém, oferecem maiores riscos de contaminação e/ou rejeição. Como exemplos desses materiais, encontram-se os tecidos de origem bovina na forma descalcificada ou não e liofilizada (CONSOLARO et al., 2004).

As membranas scaffolds biomiméticas, que imitam biologicamente a estrutura porosa da MEC nativa (DA SILVA et al., 2000), acompanham a utilização de enxertos ósseos e são classificadas como absorvíveis ou não. As absorvíveis podem ser de colágeno, poliglactina 910, osso cortical bovino liofilizado, sendo um material de fácil manuseio recomendado para preenchimento de cavidades formadas por fístulas oronasais tardias ou imediatas (GOMES et al., 2007), considerado um material de seleção celular, mantendo as células ósseas confinadas, permitindo adequada consolidação óssea (OLIVEIRA et al., 2003). Materiais metálicos são usados em forma de ligas e merecem destaque pela alta resistência mecânica à tração, ao impacto, à fadiga e ao desgaste (RIGO et al., 1999), mas possuem algumas desvantagens dependendo do tipo de material metálico, como a baixa biocompatibilidade, a corrosão em meio fisiológico, a alta densidade e a diferença de propriedades mecânicas em relação aos tecidos (WILLIAMS \& DOHERTY, 1994). Durante a manipulação de implante metálico, o procedimento é simples e rápido, comparado a um material bioabsorvível, devido à maleabilidade de maiores cuidados de implantação, fato esse observado por PYLES et al. (2007) 


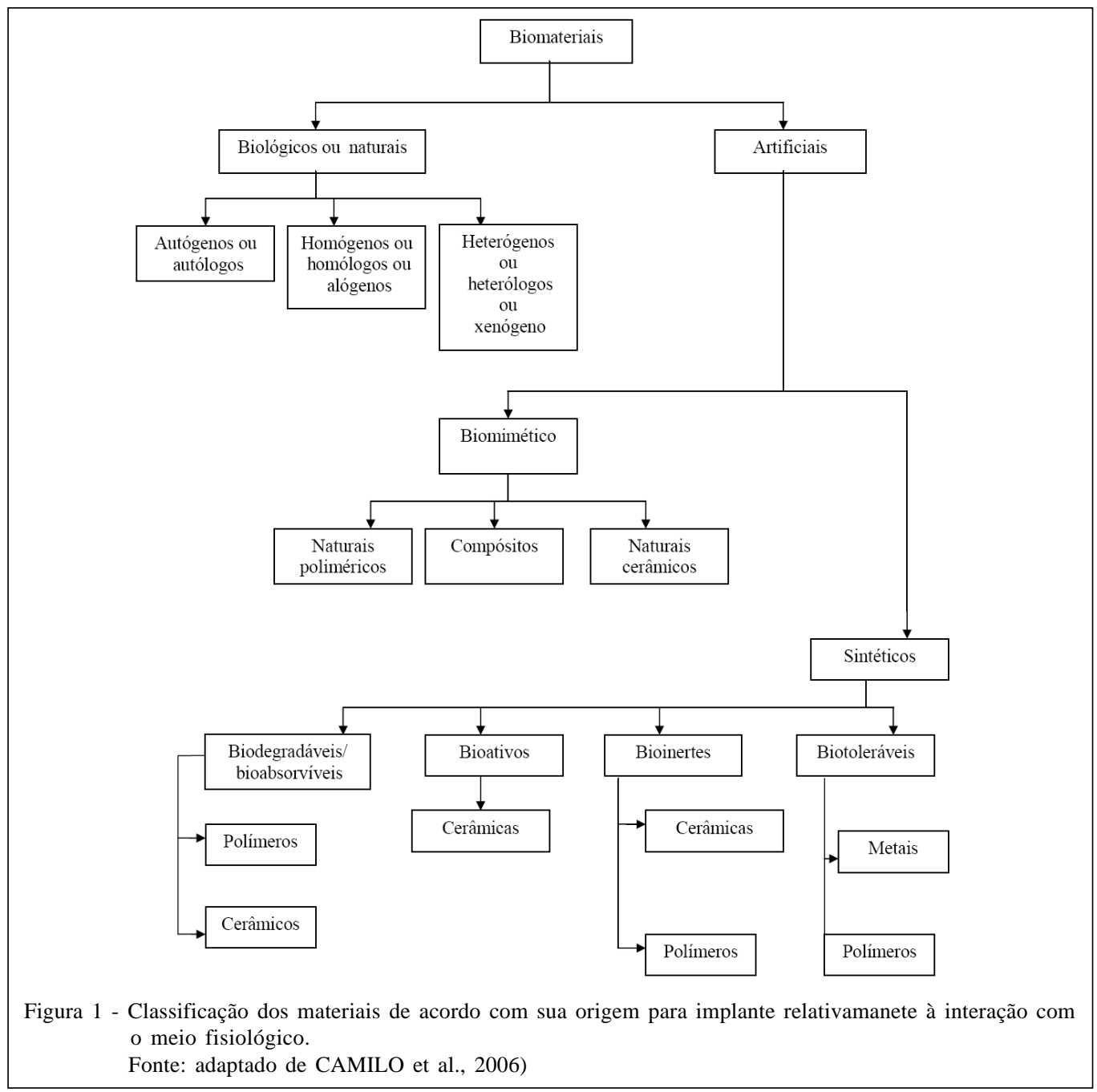

ao comparar parafusos metálicos e absorvíveis na reparação de fraturas sesamóides proximais em eqüinos. Esses pesquisadore, constataram por exames radiográficos que os implantes bioabsorvíveis possibilitam melhor remodelamento ósseo de melhor qualidade quando comparados aos metálicos.

As cerâmicas oferecem características desejáveis, tais como biocompatibilidade para utilização como implantes ósseos como a inércia química em meio fisiológico, dureza e boa resistência mecânica à compressão, porém, baixa resistência à tração. Algumas das cerâmicas mais empregadas são a alumina, a zircônia, a hidroxiapatita (MASTERS, 1988), os biovidros e os compostos de fosfatos de cálcio. A hidroxiapatita porosa foi utilizada por HOLMES et al. (1986), para o preenchimento de defeito ósseo induzido na metáfise tibial proximal de cães. O implante utilizado demonstrou um grau de crescimento ósseo, sugerindo que o receptor proporcionou células osteoprogenitoras e fatores indutivos. Os derivados inorgânicos, como a hidroxiapatita, o colágeno e o fosfato tricálcico, recebem grande atenção como materiais de preenchimento, espaçadores e substitutos para os enxertos ósseos, principalmente devido à biocompatibilidade, bioatividade e ás características de osteocondução em relação ao tecido hospedeiro (KRAUS \& KIRKEDHEAD, 2006). Contudo, CAMILO et al. (2006) relata que a hidroxiapatita sintética possui microestrutura, tamanho do cristal e tipo de ossificação muito diferente do osso natural, o que pode produzir resposta biológica indesejada.

Quanto mais extensa a espessura da camada de tecido fibroso formada, menor a tolerabilidade dos tecidos ao material. A formação de uma cápsula fibrosa na interface entre o implante e o hospedeiro deveria ocorrer somente nas fases iniciais de sua aplicação. A reação fibrosa, ao invés de proliferação celular osteoblástica, pode ser resultado de instabilidade 
mecânica ou rejeição biológica (WEISS, 1986; BARBANTI et al., 2005).

Materiais bioinerentes também são tolerados pelo organismo, com mínima formação de envoltório fibroso, e não induzem resposta local do sistema imunológico (RIGO et al., 1999). A quantidade de células fagocitárias na interface é mínima, a resposta fagocítica é passageira e uma fina cápsula toma lugar após a colocação do implante. Em alguns casos esta camada é praticamente imperceptível. As matérias que proporcionam ligações de natureza química entre o material e o tecido ósseo são bioativas e induzem a osteointegração Após certo período de tempo em contato com os tecidos, os materiais reabsorvíveis são degradados, solubilizados ou fagocitados pelo organismo, permitindo osteocondução e formação de uma ligação entre o tecido e o próprio material. (DUARTE et al., 2006).

DEL CARLO et al. (2003) observaram que matriz óssea homóloga desmineralizada não perde seu potencial quando enxertada e não inibe o potencial osteoindutor, promovendo quimiotaxia, mitose e diferenciação celular.Tais materiais como o fosfato tricálcio, a hidroxiapatita sintetizada e o ácido poliglicólico são usados em aplicações clínicas (PILLIAR et al., 2001). DÓRIA NETO et al. (2004) empregaram hidroxoapatita para preenchimento articular do carpo com alterações severas e observaram que ocorreu incorporação da hidroxiapatita e da união óssea aos 30 e 60 dias e recomendam como uma alternativa promissora como substituto para os enxertos ósseos.

Alguns materiais poliméricos como o ácido polilático e o ácido poli-glicólico (FARIA et al., 2005) ou os co-polímeros podem ser utilizados como scaffolds para promover a regeneração óssea (CAMILO et al., 2006), proporcionando mínima inflamação ao redor do implante e osteointegração em perdas ósseas (BOLSON et al., 2005). No entanto, a maior limitação desses materiais porosos à base de polímeros está em sua relativa baixa elasticidade e resistência mecânica não-compatível a aplicações em regiões articulares e substituições ósseas (CAPK et al., 1990; GRIFFITH, 2000).

Fatores que influenciam o desenvolvimento do implante

A primeira etapa na engenharia tecidual é o desenvolvimento, a seleção e o processamento dos suportes. O uso de polímeros reabsorvíveis como suporte para a cultura celular é destaque nesta área. Muitos fatores determinam a taxa de degradação dos scaffolds bioreabsorvíveis e a resposta inflamatória entre eles e o local de implante, a composição química, a cristalinidade, a morfologia, o tamanho, a porosidade, a carga da superfície, o $\mathrm{pH}$ e a presença de aditivos no implante (BOLSON et al., 2005). Na enxertia são avaliaods a vascularização local e a neovascularização, a qual serve de fonte de nutrientes e oxigênio, além de meio de condução de células fibroblásticas, contribuindo sobremaneira para o processo cicatricial (BOLTON et al., 1995). Se um scaffold for implantado em local de alta vascularização, sua osteointegração será mais rápida, comparada à região menos irrigada (DUARTE et al., 2006). De acordo com a disposição espacial das cadeias poliméricas, a cristalinidade influi a taxa de absorção de água pelo material escolhido. O primeiro estágio da degradação consiste na penetração e na difusão das moléculas de água nas regiões amorfas do material e, subseqüentemente, na união das cadeias poliméricas quando for utilizado de scaffold polimérico.

Os termos biodegradação, bioabsorção e bioreabsorção são distintos. O primeiro relaciona-se a polímeros e dispositivos sólidos, pois sofrem degradação de moléculas e também dispersão celular, mas sem estas serem eliminadas pelo organismo (BOLSON et al., 2005). Os polímeros biodegradáveis podem ser atacados por partículas biológicas de forma que a integridade do sistema seja afetada, formando fragmentos ou outros subprodutos (TAMAI et al., 2002). Em falhas ósseas induzidas experimentalmente, IGNÁCIO (1995) observou formação gradual e progressiva de neo-osso a partir das interfaces osso e polímero, iniciada por um processo inflamatório decorrente da ação do ferimento provocada pelo ato cirúrgico. Os materiais bioreabsorvidos mostraram degradação pela diminuição de tamanho, sendo reabsorvidos in vivo e eliminados por vias metabólicas. A bioreabsorção é a eliminação total do material e dos subprodutos de degradação sem efeitos colaterais. Já os bioabsorvíveis podem ser dissolvido em fluídos corpóreos sem qualquer quebra da cadeia de moléculas da reação ou diminuição da massa molecular como na lenta dissolução de implantes solúveis em fluídos orgânicos (BOSE et al., 2002).

Apesar do desenvolvimento de materiais com propriedades já descritas, uma das grandes desvantagens do uso de polímeros de origem sintética ou natural como MEC são o desenvolvimento de respostas inflamatórias e a ausência de sinais de reconhecimento celular, principalmente, em matrizes sintéticas (KIM \& MOONEY, 1998).

\section{CONCLUSÕES}

Os scaffolds são veículo que carream células para o sucesso na reconstrução de tecidos e ampliam a 
expectativa de vida do paciente. O uso de enxertos homógenos como scaffolds garante segurança e uma maior previsibilidade de resultados e serve como ferramenta cirúrgica promissora para os defeitos ósseos retardados, minimizando as complicações póscirúrgicas, além de confirmar a presença de propriedades osteocondutivas e osteoindutivas com capacidade regenerativa comparável ao calo ósseo autógeno. Embora revolucionária, a engenharia de tecidos tem suas limitações. As grandes perspectivas de avanço das técnicas de cultura celular progenitoras ou aplicação de células in natura ou in vitro e dos suportes utilizados ainda não permitem que os tecidos e órgãos sejam reproduzidos com toda a complexidade fisiológica.

\section{REFERÊNCIAS}

BARBANTI, S.H. et al. Bioabsorbable polymers in tissue engineering. Polimeros: Ciência e Tecnologia, v.15, n.1, p. 13-21, 2005.

BARRY, F.P. Biology and clinicall applications of mesenchymal stem cells. Birth defects Research Part C: Embryo Today, v.69, p.250-256, 2003.

BENSAÏDE, W. et al. A biodegradable fibrin scaffold for mesenchymal stem cell transplantation. Biomaterials, v.24, n.14, p. 2497-2502, 2003.

BLACKSHAW, S.E. et al. Promotion of regeneration and axon growth following injury in an invertebrate nervous system by the use of three-dimensional collagen gels. Proceedings of the Royal Society of London Series B - Biological Sciences, v.264, n.1382, p.657-661, 1997.

BOLTON, P. et al. The direct effect of $860 \mathrm{~nm}$ light on cell proliferation and on succinic dehydrogenase activity of human fibroblast in vitro. Laser Therapy, v.7, p.55-60, 1995.

BOSE, S. et al. Processing and characterization of porous alumina scaffolds. Journal of Materials Science: Materials in Medicine, v.13, p.23-28, 2002.

BOLSON, J. et al. Análise clínica, radiológica, macroscópica e histológica do úmero de codornas domésticas (Coturnix japonica), submetido ao implante da poliuretana derivada do polímero de mamona (Ricinnus communis). Ciencia Rural, v.35, n.5, p.1123-1130, 2005.

BRUDER, S.P.; FOX, B.S. Tissue engineering of bone. Cell based strategies. Clinical Orthopaedic, v.367, p.68-83, 1999.

BRUN, M.V. et al. Solução hipersaturada de sal como conservante de pericárdio canino utilizado na reparação do músculo reto abdominal de ratos wistar. Ciência Rural, v.32, n.6, p.1019-1025, 2002.

BURG, K.J. et al. Biomaterial developments for bone tissue engineering. Biomaterials, v.21, n.23, 2347-2359, 2000.
CAMILO, C.C. et al. Escafoldes para implantes ósseos em alumina/hidroxiapatita/biovidro: análises mecânica e in vitro. In: CONGRESSO LATINO AMERICANO DE ÓRGÃOS ARTIFICIAIS E BIOMATERIAIS, 4., 2006, Caxambú. Anais... Caxambú: IV COLAOB, 2006. p.28-34

CANCEDDA, R. et al. Tissue enginnering and cell therapy of cartilage and bone. Matrix Biological, v.22, p.81-91, 2003.

CAPK, G. et al. Chemitry of calcium phosphate bioceramics. In: YAMAMURO, T. et al. Handbook on bioactive ceramics. Boca Raton, FL: CRC, 1990. V.II, p.31.

CAPLAN, A.; BRUDER, S.P. Mesenchymal stem cells: building blocks for molecular medicine in the $21^{\text {st }}$ century. Trends Molecular in Medicine, v.7, p.259-264, 2001.

CONSOLARO, A. et al . Avaliação de implantes de osso bovino osseobond e membrana reabsorvível de osso bovino liofilizado. 07 de abril de 2004. Capturado em 16 de abril de 2007. Online. Disponível na internet http:// www.odontologia.com.br.

CONTESINI et al. Implante de traquéia de gallus domesticus na microsanastomose arterial em cães. Acta Scientiae Veterinariae, Porto Alegre, v.32, n.2, p.89-95, 2004.

COOPER, L.F. et al. Incipients analysis of mesenchymal stemcell-derived osteogenesis. Journal of Dental Research, v.80, p.314-320, 2001.

DA SILVA, A.M. et al. Aspectos macro e microscópicos da fascia lata utilizada como substituto autógeno do ligamento cruzado cranial. Ciência Rural, v.30, n.2, p.275-280, 2000 .

DASSO, G. et al. Allogeneic bone grafts treated with different conservation methodsfor bone repair in rabbits. Archivos de Medicina Veterinária, v.30, n.2, p.57-66, 1998.

DEL CARLO, R.J. et al. Osteoinductivity of demineralized homologous bone graft in rabbits. Ciência Rural, v.33, n.3, p.533-538, 2003.

DEUEL, T.F. Introduction in tissue engineering. In: LANZA, R.P. et al. Principles of tissue engineering. San Diego: Academic, 1997 . p.133-149.

DÓRIA NETO, F.A. et al. Arthrodesis of the carpus in cats associeted with hydroxyapatite. Ciência Rural, v.34, n.3, p.931-934, 2004.

DUARTE, T.S. et al. Osteointegração da hidroxiapatita sintética no processo alveolar da mandíbula de cães: aspectos histológicos. Arquivos Brasileiros de Medicina Veterinária e Zootecnia, v.58, n.5, p.849-853, 2006.

EDWARDS, S.L. et al. Design of nonwoven scaffold structures for tissue engineering of the anterior cruciate ligament. Research Journal, v.4, n.2, p.86-94, 2004.

FARIA, T.J. et al. Preparation and characterization of poly (D,L-lactide) (PLA) and poly (D,L-lactiode)-poly (ethyleneglycol) (PLA-PEG) nanocapsules containing antitumoral agent methotrexate. Macromolecular Symposia, v.229, p.228-233, 2005. 
GIOSO, M.A. et al. Análise microbiológica de ossos de cães conservados por longo período de tempo na glicerina a $98 \%$ à temperatura ambiente, objetivando a enxertia óssea. Acta Cirúrgica Brasileira, v.17, n.4, 2002.

GLOWACKI, J. Tissue response to bone derived implants. In: HABAL, M.B.; REDDI, A.H. Bone grafts and bone substitutes. Philadelphia: Saunders, 1992. p.84-91.

GOLDBERG, M. et al. Proteoglycans in predentin: the last 15 micrometers before mineralization. Connective Tissue Research, v.44, p.184-188, 2003.

GOMES, M.E. et al. Effect of flow perfusion on the osteogenic differentiation of bone marrow stromal cells culture on starch-based threedimensional scaffolds. Journal Biomedical Materials Research, v.67A, p.8795, 2003.

GOMES, M.M.E. A bone tissue engineering strategy based on starch scaffolds and bone marrow cells cultured in a flow perfusion bioreactor. 2004. 198f. T ese (Doutorado em Ciência e Tecnologia de Materiais) - Faculdade de Engenharia, Universidade do Minho.

GOMES, K. et al. Lyophilized inorganic bovine bone cancellous block for iatrogenic oronasal fistula repair in dogs. Ciência Rural, v.31, n.1, p.159-164, 2007.

GRIFFITH, L.G. Polymeric biomaterials. Acta Materialia, v.48, n.1, p.263-277, 2000.

GUPTA, B.S.; KASYANOV, V.A. Biomechanics of human common carotid artery and design of novel hybrid textile compliant vascular grafts. Journal of Biomedical Materials Research, v.34, n.3, p.341-349, 1997.

HABAL, M.B. Different forms of bone grafts. In: HABAL, M.B; REDDI, H.D. Bone grafts and bone substitutes. Philadelphia: Sauders, 1992. p.6-8.

HAYNESWORTH, S.E. et al. Characterization of cells with osteogenic potential from human marrow. Bone, v.13, p.8188, 1992.

HENCH, L.L. Bioceramics. Journal of the American Ceramic Society, v.81, n.7, p.1706-1733, 1998.

HERCULIANI, P.P. et al. Tratamento de defeito ósseo perene em calvária de cobaia com membrana de cortical óssea bovina liofilizada associada ou não a enxerto ósseo desmineralizado. Revista Brasileira de Implantes, v.17, n.2, p.7-14, 2000

HOLMES, R.E. et al. Porous hydroxyapatite as a bone graft substitute in metaphyseal defects : a histometric study. Journal Bone Joint Surgery, v.68A, n.4, p.904-911, 1986.

HOLMES, T.C. Novel peptide-based biomaterial scaffolds for tissue engineering. Trends in Biotechnology, v.20, n.1, p.132137, 2002.

IGNÁCIO, H. Utilização do cimento derivado da mamona no preenchimento de falhas ósseas: estudo experimental em coelhos. 1995. 90f. Dissertação (Mestrado em Ortopedia e Traumatologia) - Faculdade de Medicina, Universidade de São Paulo.
JAISWAL, N. et al. Osteogenic differentiation os purified, culture-expanded human mesenchymal stem cells in vitro. J ournal Cell Biochemical, v.64, p.295-312, 1997.

KIM, B.S.; MOONEY, D.J. Development of biocompatible synthetic extracellular matrices for tissue engineering. Trends in Biotechnology, v.16, n.5, p.224-230, 1998.

KRAUS, K.H.; KIRKED-HEAD, C. Mesenchymal stem cells and bone regeneration. Veterinary Surgery, v.35, p.232242, 2006

LANGER, R.; VACANTI, J.P. Tissue engineering. Science, v.260, n.5110, p.920-926, 1993.

LUTOLF, M.P. et al. Repair of bone defects using synthetic mimetics of collagenous extracelular matrices. Nature Biotechnology, v.21, n.5, p.513-518, 2003.

MASTERS, D.H. Implants. Bone and bone substitutes. Journal California Dental Association, v.16, p.56-65, 1988.

MARTINEZ, E.F.; ARAÚJO, V.C. In vitro immunoexpression od extracellular matrix proteins in dental pulpal and gingival human fibroblasts. International Endodontic Journal, v.37, n.11, p.749-755, 2004

MATSUI, S. Histological evaluation of skin reconstruction using artificial dermis. Biomaterials, v.17, n.10, p.995-1000, 1996.

MUSCHLER, G.F.; MIDURA, R.J. Connective tissue progenitors: practical concepts for clinical applications. Clinical Orthopedic, v.395, p.66-80, 2002.

NARDI, N.B.; MEIRELLES, L.S. Mesenchymal stem cells: Isolation in vitro expansion and characterization. Handb Exp Pharmacol, v.174, p.249-282, 2006.

OLIVEIRA, G.K. et al. Identificação de células-tronco mononucleares através de nanocristais Q-tracker em tecido ósseo de cães. In: SIMPÓSIO MULTIDISCIPLINAR SOBRE CÉLULAS-TRONCO, 2., 2007, São Paulo, SP. Anais... São Paulo: II SIMPÓSIO MULTIDISCIPLIANR SOBRE CÉLULASTRONCO-SP, 2007. CD-ROM.

OLIVEIRA, R.C. et al. A valiação histológica e bioquímica da resposta celular ao enxerto de osso cortical bovino previamente submetido a altas temperaturas. Efeito da temperatura no preparo de enxerto xenógeno. Acta Ortopédica Brasileira, v.38, n.9, p.551-560, 2003.

OLSSON, D.C. et al. Matriz óssea alogênica conservada em mel como scaffold para células-tronco da medula óssea no tratamento de união retardada - relato de caso. In: SALÃO DE INCIAÇÃO CIENTÍFICA, 19; FEIRA DE INICIAÇÃO CIENTÍFICA, 16.; SALÃO UFRGS JOVEM, 2., 2007, Porto Alegre, RS. Anais... Porto Alegre: XIX SALÃO DE INCIAÇÃO CIENTÍFICA - RS, 2007. CDROM.

OONISHI, H. et al. Particulate bioglass compared with hydroxyapatite as a bone graft substitute. Clinical Orthopaedical \& Related Research, n.334, p.316-325, 1997. 
PARTRIDGE, K. et al. Adenoviral BMP-2 gene transfer in mesenchymal stem cells: in vitro and in vivo bone formation on biodegrable polymer scaffolds. Biochemical and Biophysical Research Communications, v.292, p.144152, 2002.

PAGLIOSA, G.; ALVES, G.E.S. Considerações sobre a obtenção e o uso do plasma rico em plaquetas e das células mesenquimais indiferenciadas em enxertos ósseos. Ciência Rural, v.37. n.4, p.1202-1205, 2007.

PILLIAR, R.M. et al. Porous calcium polyphosphate scaffolds for bone substitute application - in vitro characterization. Biomaterials, v.22, p.963-972, 2001.

PYLES, M.D. et al. Bioabsorbable screws in the healing of experimentally induced fractures of the proximal sesamoid bonein horses. Ciência Rural, v.37, n.5, p.1367-1373, 2007.

RAISER, A.G. et al. Redução de fenda palatina com resina acrílica autopolimerizável em um gato. A Hora Veterinária, v.21, n.121, p.50-52, 2001.

RAO, K.P. Recent developments of collagen-based materials for medical applications and drug delivery systems. Journal of Biomaterials Science Polymer, v.7, n.7, p.623-645, 1995.

RIGO, E.C.S. et al. Implantes metálicos recobertos com hidroxiapatita. Revista de Engenharia Biomédica, v.15211529, 1999.

SAKIEL, S. Clinical application of new bovine collagen membranes as a partial-thickness burn wound dressing. Polymers \& Medicine, v.25, n.3/4, p.19-24, 1995.
SALBEGO, F. et al. Correção de perda óssea segmentar por implante ósseo cortical preservado em glicerina a 98\% em cães associado a inoculação de células-tronco autógenas. In: JORNADA ACADÊMICA INTEGRADA DA UFSM, 22., 2007, Santa Maria, RS. Anais... Santa Maria: UFSM, 2007. CDROM.

SERAKINCI, N.; NICOL, K.W. Therapeutic potential of adult stem cells. European journal of cancer, v.42, n.99, p.12431246, 2006.

SOARES, G.A. Biomateriais. Forum de Biotecnologia Biomateriais. Programa de engenharia metalúrgica e de materiais. Rio de Janeiro: Universidade Federal do Rio de Janeiro. 2005. $84 p$.

TAMAI, T. et al. Novel hidroxyapatite ceramics with in interconnective porous structure inhibit superior osteoconduction in vivo. Journal Biomedical Materials Research, n.59, p.110-117, 2002.

TENÓRIO, D.M.H. Distribution of biglycan and decorin in rat dental tissue. Brazilian Journal of Medical and Biological Research, v.36, n.8, p.1061-1065, 2003.

THOMAS, X.; ANGLARET, B. Cell adhesion molecules: expression and function in acute myeloid leukemia. Bulletin du Cancer, v.88, p.265-277, 1999.

WEISS, C.M. Tissue integration of dental endosseous implants: description and comparative analysis of the fibro-osseous integration and osseous integration systems. Journal Oral Implantology, v.12, n.2, p.169-214, 1986.

WILLIAMS, R.L.; DOHERTY, P.J. A preliminary assessment of poly(pyrrole) in nerve guide studies. Journal of Materials Science: Materials in Medicine, v.5, n.6/7, p.429-433, 1994. 